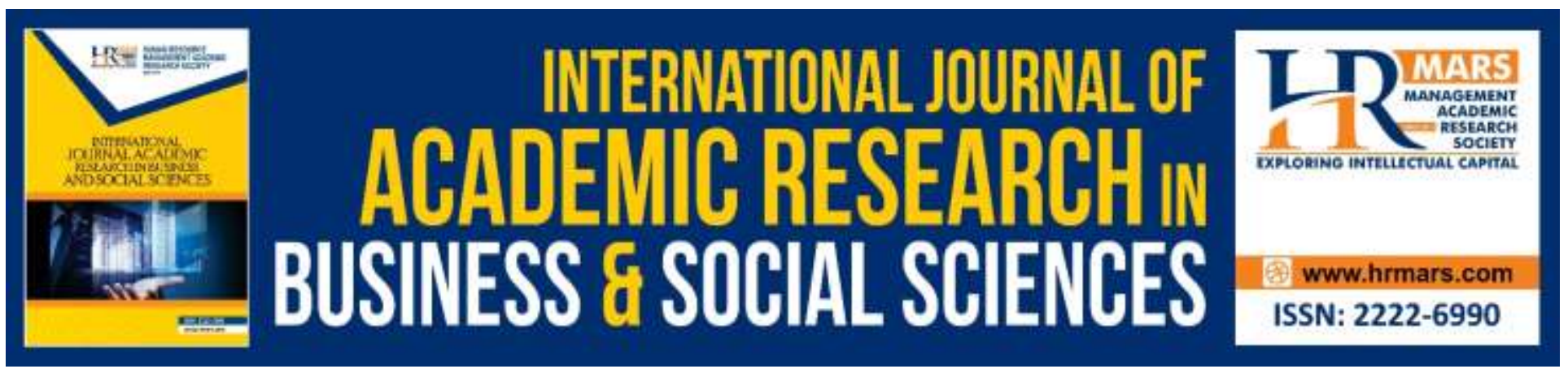

\title{
Application of The Wellbeing Theory on Air Traffic Controllers: A Model on How to Flourish in Practice at The Workplace
}

Shafazawana Mohamed Tharikh and Siti Raba'ah Hamzah

To Link this Article: http://dx.doi.org/10.6007/IJARBSS/v10-i5/7225

DOI:10.6007/IJARBSS/v10-i5/7225

Received: 14 March 2020, Revised: 16 April 2020, Accepted: 28 April 2020

Published Online: 21 May 2020

In-Text Citation: (Tharikh \& Hamzah, 2020)

To Cite this Article: Tharikh, S. M., \& Hamzah, S. R. (2020). Application of The Wellbeing Theory on Air Traffic Controllers: A Model on How to Flourish in Practice at The Workplace. International Journal of Academic Research in Business and Social Sciences, 10(5), 522-532.

\section{Copyright: (c) 2020 The Author(s)}

Published by Human Resource Management Academic Research Society (www.hrmars.com)

This article is published under the Creative Commons Attribution (CC BY 4.0) license. Anyone may reproduce, distribute, translate and create derivative works of this article (for both commercial and non-commercial purposes), subject to full attribution to the original publication and authors. The full terms of this license may be seen

at: http://creativecommons.org/licences/by/4.0/legalcode

Vol. 10, No. 5, 2020, Pg. 522 - 532

Full Terms \& Conditions of access and use can be found at http://hrmars.com/index.php/pages/detail/publication-ethics 


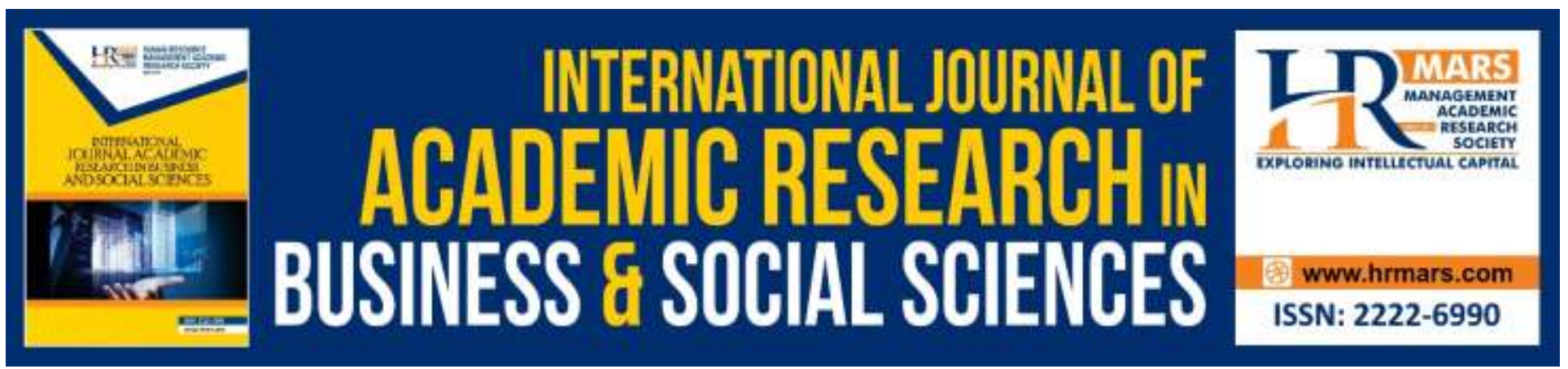

\title{
Application of The Wellbeing Theory on Air Traffic Controllers: A Model on How to Flourish in Practice at The Workplace
}

\author{
Shafazawana Mohamed Tharikha and Siti Raba'ah Hamzah ${ }^{\mathrm{b}}$ \\ ${ }^{a}$ College of Business Management and Accounting, University Tenaga Nasional, MALAYSIA \\ ${ }^{\mathrm{b}}$ Faculty of Education, University Putra Malaysia, MALAYSIA \\ Email:shafa@uniten.edu.my
}

\begin{abstract}
Wellbeing is a persistent scope of positive feelings and subjective life assessments for each person which generally utilized conversely with bliss. People react differently to similar conditions, and they assess conditions subject to their unique wants, moral, culture and past experiences. Supporting and empowering wellbeing has the ability of benefiting both the employees and the organization. The wellbeing of employees is basic for the endurance and improvement of organizations worldwide. Wellbeing at work requires basic needs to be met and improved by conditions that incorporate supportive personal relationships, community empowerment, healthy and alluring environment. In Wellbeing Theory (WBT), there are five pillars which known as PERMA (P-positive emotion, Eengagement, $\mathrm{R}$ - relationship, $\mathrm{M}$ - meaning and $\mathrm{A}$-achievement). Each one of the pillars is not clinical as it gives escalation to a higher-order construct of wellbeing that should then expect flourishing of everyone at the workplace.
\end{abstract}

Keywords: Wellbeing Theory, PERMA Model, Air Traffic Controllers, Employee Wellbeing.

\section{Employee Wellbeing}

Wellbeing is a construct of physical, social and mental state which originates from a large group of collective goods and relations with individuals and places. It is a pack needs that must be met and enriched by the conditions (Bakar et al., 2015). Wellbeing in this study, conveys information with respect to a wide scope of mental health, social connections, leisure, and subjective states such as emotions and mental engagement. The significance of wellbeing has been perceived not just in scholastic fields but also in public policy and occupational settings for encouraging human capital, profitability and productivity (Watanabe et al., 2018). The Malaysian government viewed wellbeing is crucial and need to be given attention, thus Malaysia Wellbeing Index (MWI) for year 2013 was assessed and reported. Wellbeing in particular highlights the mental and physical health of a collective group and the economic advantages that prompts the headway in the fulfillment of people and their contentment among family and the societies (Yogeesvaran, 2013). 
Wellbeing activities at work must be suitable with the needs and wants of every employee in the workplace (Tehrani et al., 2007), whilst the Economic Planning Unit (EPU) in 2015 concentrated on occupation fulfillment as well as life contentment, as happiness will be derived directly from employment satisfaction or work life.

In order to carry out a sensible and generous assessment, it is coherently perceive what is assessed for employee wellbeing and how the outcomes ought to be deciphered (Dodge et al., 2012). Clearly, most organizations need to accomplish their execution (Zakaria et al., 2014). However, there are various factors concentrating on execution, such as, the employees' wellbeing, ought not be excused and attention should continue being paid on it (Duygulu et al., 2013; Juniper et al., 2011; Slemp \& Vella-Brodrick, 2013).

\section{Air Traffic Controllers}

Industry such as aviation has strong impact towards other industries (Mahzan \& Abidin, 2015; Moon, Yoo \& Choi, 2000) particularly in developing countries like Malaysia. It is an extremely intricate technology-centric industry which needs profoundly specialized and skilled employees (Kuo, Jou, \& Lin, 2012; Teperi, Leppänen, \& Norros, 2015) to work in a quick pace inventive and innovative technology environment which is continuously evolving. The employees are exceptionally prepared experts (Brink, 2009; Kontogiannis \& Malakis, 2013). They should pass certain test in competencies such as personality test, physical and mental health test and must be fluent in conversational English (Basu, Mitchell, \& Sabhnani, 2009; Moon, Yoo \& Choi, 2011). Air traffic control all over the world is a 24-hour operation including public holidays and weekends leading to air traffic controllers (ATCS) working in shifts and at night regularly (CAAM, 2018; FAA, 2018).

The main job responsibility of ATCs is to control and navigate the movement of planes particularly during take-off and landing (Kontogiannis \& Malakis, 2013; Tobaruela et al., 2014). As they are working in shifts, it implies that they work outside the ordinary hours. It prompts pressure and fatigue resulting to effect ATCs' wellbeing if the shift schedules are not organized deliberately in terms of their shift length, rest breaks and consecutive shifts (Dall'Ora et al., 2016; Folkard, Robertson $\&$ Spencer, 2007). This could contribute to pressure and strain to air traffic management agencies and the industry as a whole.

\section{Problem Statement}

ATCs can be categorized as a very stressful occupational group (Sanda, 2018; Tomic \& Liu, 2017; US Department of Labor \& Bureau of Labor Statistics, 2010). The successful passing of certain competency test still does not guarantee that ATCs could sustain a good wellbeing at the workplace. ATCs are confronted with multiple times higher of hypertension contrasted with the others typical for their age group (Ćosić et al., 2019). This is due to their quantitative demand, decision demand and learning demand which have diverse scope from other occupations (Falkland, Emma \& Wiggins, 2019). The high-end technology systems used in air traffic management settings still could not cope with the heavy workload and mental demand (Öge, Cetin, \& Top, 2018).

At the point when the unpredictability of the aviation industry expands, ATCs can become overpowered with traffic and it will influence the way they perform their work (Tobaruela et al., 2014; Tomic \& Liu, 2017; Yang \& Dattel, 2017). In commercial aviation mishaps, 70\% are ascribed to human 
errors, making human factor as the final frontier in improving aviation safety (Bongo et al., 2018; Kontogiannis \& Malakis, 2013; Teperi et al., 2015). In response to such errors and accidents, many researchers have centered their efforts to create tools to prevent human errors among ATCs (e.g. Teperi et al., 2015), yet almost no studies have been conducted to develop and improve the ATCs' wellbeing. Notwithstanding that, ATCs felt secluded as an occupational group (Brink, 2009; Tomic \& Liu; 2017) as most researchers have given their attention to other unit analysis (e.g. Teachers, doctors, nurses and the police).

Antecedently, the vast majority of the wellbeing studies were underpinned by theories such as the set-point theory (e.g. Page \& Vella-Brodrick, 2009), Maslow's theory (e.g. Benjamin et al., 2014) and the conservation of resources theory (e.g. Avey, 2010) which progressively centered on subjective wellbeing and psychological wellbeing. Wellbeing Theory (WBT) has not been completely constituted in a varied range of populations (Coffey et al., 2016) such as ATCs. Most of the studies on WBT were conducted on wellbeing among undergraduates such as in the United States (Coffey et al., 2016) United Arab Emirates (D'raven \& Pasha-Zaidi, 2016), Australia (Kern et al., 2015), workers in higher educational institutions in Malaysia (Othman et al., 2018) however not to employee wellbeing among ATCs.

\section{Wellbeing Theory (WBT)}

There are five pillars in WBT which is abbreviated as PERMA (P-positive emotion, Eengagement, R- relationship, $\mathrm{M}$ - meaning and $\mathrm{A}$-achievement). Each of the pillar is not clinical as it gives escalation to a higher-order construct of wellbeing that should then expect flourishing of everyone in the world (Forgeard et al., 2011; Seligman, 2012; Yogeesvaran, 2013). This is plausible as each of the pillars in the theory provides the constituent elements to define and clarify the psychosocial work environment factors and employee wellbeing that matches the ATCs work environment. In other words, the variables of interest must be defined using the pillars as opined in the theory to elucidate physically and mentally fit ATCs and the drivers that create and sustained the physically and mentally fit ATCs.

The five pillars of PERMA differentiate WBT from other multidimensional theories as it includes both subjective wellbeing (positive emotion and engagement) and psychological wellbeing (relationship and meaning). It also includes unique components in workplace wellbeing such as advance skill and achievement (accomplishment) that are frequently excluded in other theories of wellbeing (Butler \& Kern, 2016; Othman et al., 2018).

Positive emotions in WBT refers to bliss, for example joy and happiness (Forgeard et al., 2011; Seligman, 2012). The positive emotions will increase the attention of a person, driving them to be innovative, improve adaptable thoughts, and equip individuals to be ready at all time (D'raven \& Pasha-Zaidi, 2016). Positive emotion in WBT is believed to guide employees to enjoy whatever job tasks they received at their working place. When employees are happy, they tend to engage with the employer and get themselves loyal by working with the organization besides improving the productivity. WBT is only focusing on positive emotion, however, to capture both positive and negative sides of the mental health spectrum, the negative emotion is included at the workplace (Diener, Oishi \& Tay, 2018). The fused negative inclination is added in due to the nature of work, for instance, routinizing, supervision and multifaceted nature, is casually associated with the sentiment 
of control and sadness of an individual (Kuovo, 2016; Coffey et al., 2016; Harter et al., 2003). Workplace stress can have such an enormous number of negative consequences for employees, for example, rejection, decrease in profitability and increase in hypertension (Diener, Oishi \& Tay, 2018). According to Salvin et al. (2012), mindfulness-based stress-reduction programs can be one of the effective programs in reducing distress. Hence, to develop a healthy workplace plan, it is suggested to the Malaysian ATCs that they be actively involved in programs or activities initiated by the Malaysian Mental Health Association (MMHA) to ensure that ATCs are aware regarding their own mental health and to be monitored continuously by the management.

Engagement can be defined as being totally immersed in activities and experiencing a feeling of being absorbed or extraordinary enthusiasm in the organization (Coffey et al., 2016; Seligman, 2012). It is also known as character strength or positive traits that can reflect actions, thoughts and emotions (D'raven \& Pasha-Zaidi, 2016). In order to be totally caught up in workplace activities, despite the equipment and materials provided at work, the endeavor itself and the intensity of human resources play an imperative role in ensuring compelling commitment, as it can extend the obligations and execution of employees (Bakker, 2015). Employees should be given the chance to connect completely in their work through decrease of non-value work, decrease of unneeded policies, and the contour of administrative processes (Slavin et al., 2012). In addition to that, Human Resource Development (HRD) could likewise create special training and program for example showing shift-workers strategies (i.e. ATCs) to deal with their sleep schedules and conducting ergonomics assessment and how job tasks are led. The HRD ought to guarantee that every organization should design and determine initiatives on how to use on-site personnel, physical assets and organizational competences. Essential spotlight is on the employees' needs which a working environment wellbeing advancement program should meet the needs for all levels of employees, regardless of their present level of health. It should perceive the necessities, preferences and attitudes of various groups of employee contribution or it can create special reasonable features for every working environment.

The relationship is really about connectivity to other individuals or in other words; socially integrated (Seligman, 2012). At work, the relationships with colleagues and superiors are crucial to ensure that they achieve the organizations' mission and vision (Ashkanasy \& Dorris, 2017). As Hetland et al. (2011) observed that the work environment is a field for superiors and staff to feel associated. When somebody is overwhelmed, they are compelled to trust, realize or act in certain ways (Meyer \& Maltin, 2010). In a similar vein, Hetland et al. (2011) found that employees' wants and working environment fulfillment were emphatically ascribed to work satisfaction. Based on WBT, there are basic psychological needs in psychological wellbeing such as good relationship with the leaders and co-workers when fulfilled will lead to fundamental human need fulfillment(Tansey et al., 2018). By allowing ATCs to work more comfortably, the suggested improvements will increase positive wellbeing among ATCs. Key personnel such as the supervisors of ATCs, should postulate extensive guidelines to regulators for regulating better indicators and workload of ATCs' psychosocial work environment factors as they are among the closest person that is well versed with the scenarios of their working styles. Managing workload should be good in practice to guarantee that employees' errands and duties can be practiced effectively within the time available. At the point when 
employees appreciate and feel associated with their work and where they feel aroused, they will carry out their responsibility well.

Another WBT pointer is called meaning which is a feeling of direction resulting from something observed as more prominent than self (Seligman, 2012) yet towards the satisfaction of something perceived to be significant such as esteeming and advancing wellbeing, networking with the community, political and creating important associations with family for instance (D'raven \& Pasha-Zaidi, 2016). Individuals have meaning since it makes life worth living and gives them a feeling of satisfaction that goes forever (Coffey et al., 2016). It brings individuals to be best functioning in both personal and working lives when they have a sense of meaning or purpose, defined in terms of having a good path and feeling that what one does is valuable. Meaning is firmly related with selfesteem, self-acceptance, emotional regulation and lower risk for substance misuse and fixation (Khwaja, 2020). Three viewpoints of meaning recommended by Khwaja (2020); it is found through making work an accomplishment, experience and a mentality we take towards unavoidable torment. The organization can appoint counselors among ATCs as they understand the nature of work, so that ATCs have a medium to speak to or rely on whenever they feel stress or demotivated. In addition to that, the management can outline more programs or training specifically to boost ATCs self-efficacy and their self-esteem so that they can develop their positive wellbeing or their meaning being in a family of ATCS. Furthermore, the organization should implement a forum of small groups of employees to discuss knowledge and ideas around a specific topic. It is also beneficial for the organization to make available a "people directory" to locate employees with a given expertise to ensure their wellbeing is always positive.

The fifth indicator of WBT is accomplishment which involves making progress towards specific or fixed organizational goals, feeling capable to do daily tasks and activities, and having a sense of achievement (D'raven \& Pasha-Zaidi, 2016; Kern et al., 2015) which affect the wellbeing of employees. Moreover, the contrast between every individual can have diverse qualities and act contrastingly in each circumstance (Coffey et al., 2016; Seligman, 2012). Thus, achievement as an important driver of wellbeing that should be operationalized by examining the desire of individuals to achieve something instead of inspecting the real accomplishments (Coffey et al., 2016; Kern et al., 2014; Seligman, 2012; Othman et al., 2018). Coined by Khwaja (2020), goals can be visualized to be a great cue to remind employees and motivate them to see the bigger picture. All employees in every organization rely upon one another (superiors and subordinates) as they are cooperating for the larger purpose. This establishes a culture of dependability and esprit de-corp which prevails as exemplify from the analysis and informal observations leading to the attainment of key performance specifications among the ATCs fraternity. At the point when people work together under an organization for the shared objectives, it brings solidarity which provide the ground for the improvement of psychosocial work environment factors at the workplace, thus contributing to wellbeing.

Recently, Othman et al. (2018) stated that academicians are expected to do multitasking work example teaching, supervision, publication, administration work, and consulting students. Researchers have found that WBT fit the focus group study among academician in Malaysia. Nevertheless, there was an extra input that did not fit into the model and had to be prescribed under 
a different theme, which was named as infrastructure which covered facilities, maintenance and monitoring.

Most of the studies on WBT have been conducted among teachers (Coffey et al., 2016), students (Tansey et al., 2018), academicians (Othman et al., 2018) and nurses (Khwaja et al., 2020). Due to the limited studies of WBT on ATCs, this is the main reason why the WBT should extend the theory into Malaysia's population, specifically to the working environment of ATCs in Malaysia.

Therefore, considering the above statement, this study generally attempts to investigate the psychosocial work environment factors and employee wellbeing among ATCs in Malaysia. Whilst the specific research objectives for this study are formulated as follows;

I. To determine the relationship between leadership style of superiors and employee wellbeing among ATCs in Malaysia.

II. To determine the relationship between leadership style of superiors and employee wellbeing among ATCs in Malaysia.

Hence, the following theoretical framework has been proposed from WBT to flourish in practice at the ATCs' workplace.

Figure 1. Theoretical Framework

\begin{tabular}{|c|c|}
\hline $\begin{array}{l}\text { Psychosocial Work Environment Factors } \\
\text { - Leadership Style } \\
\text { - Work Conditions }\end{array}$ & $\begin{array}{ll} & \text { Employee Wellbeing } \\
\text { - } & \text { Subjective Wellbeing } \\
\text { - } & \text { Psychological Wellbeing } \\
\text { - } & \text { Workplace Wellbeing }\end{array}$ \\
\hline
\end{tabular}

\section{Conclusion}

The WBT explained well that the positive of employee wellbeing could be reached by strategically exploiting the individual's happiness. The culture of the organization will shape the desires for employees, as they notice autonomous work and leaders makes them feel progressively committed, vivacious and enjoyment in their employments. The study framework entails important messages to practitioners at the workplace to consider the concerns of the ATCs and knowledgeable individuals that are able to elevate the organization to the next level. Thus, this study contributed to the practical use of WBT in an integrative manner in the understanding of the phenomenon of employee wellbeing among a group of ATCs.

\section{Theoretical and Contextual Contribution}

This study offers a cognizance of the variables and their relationships for theory development on the subject matter, workers' profession movement choices, organizational practices and national policy. Due to the crucial jobs of ATCs, an investigation on factors affecting their wellbeing dependent on the psychosocial work environment factors must be conducted. This study should provide added value for the theoretical evolution of the subject and contextual contribution. 
INTERNATIONAL JOURNAL OF ACADEMIC RESEARCH IN BUSINESS AND SOCIAL SCIENCES Vol. 10, No. 5, May, 2020, E-ISSN: 2222-6990 @ 2020 HRMARS

The investigation from this viewpoint seeks to diminish the research gap which is deficient in empirical evidence to capture the association between the independent variables and employee wellbeing. Consideration and support for wellbeing is progressively foreseen as an interdisciplinary issue that should be given more attentions at different levels within a system, including individuals, employees and management, societies, and nations (Butler \& Kern, 2016). Some theories were just concentrating on hedonic elements such as emotions, while some underline only on eudemonic components such as self-actualization but the WBT has consolidated both eudemonic (psychological wellbeing) and hedonic (subjective wellbeing) elements.

For the theoretical evolution, this study broadens the limitation of past studies (e.g. Zheng et al., 2015) on psychosocial work environment factors by incorporating other related variables such as the work environment and leadership styles of superiors to explain the phenomenon of employee wellbeing specifically among the ATCs.

With respect to context, this study will help human resource development (HRD) researchers, leaders and practitioners in understanding the issue of wellbeing. The results of the study could be utilized to help them in advocating wellness and wellbeing program, provide adequate training and leaders training relating to employee wellbeing. Moreover, this study includes practices in HRD which can be implemented to explain the expansion in HRD obstructions and practices in a more extensive setting of individuals and their career development or profession advancement. This may also lead to the appointment of counselors among former ATCs since they knew the job and duties of ATCs well.

It is hoped that this study will provide more informed link between theory and practice to address the present gaps in the literature today. The discoveries made in this study should be applicable to the aviation industry in outlining their strategies to address the issues with respect to the wellbeing of employees in order to achieve a win-win situation for the organization and its employee.

\section{References}

Ashkanasy, N. M., \& Dorris, A. D. (2017). Emotions in the workplace. Annual Review of Organizational Psychology and Organizational Behavior, 4, 67-90. https://doi.org/10.1146/annurevorgpsych-032516-113231

Avey, J. B., Luthans, F., Smith, R. M., \& Palmer, N. F. (2010). Impact of positive psychological capital on employee well-being over time. Journal of occupational health psychology, 15(1), 17. https://psycnet.apa.org/doi/10.1037/a0016998

Bakar, A. A., Osman, M. M., Bachok, S., Ibrahim, M., \& Mohamed, M. Z. (2015). Modelling economic wellbeing and social wellbeing for sustainability: a theoretical concept. Procedia Environmental Sciences, 28, 286-296. https://doi.org/10.1016/j.proenv.2015.07.037

Bakker, A. B. (2015). Towards a multilevel approach of employee well-being. European Journal of Work and Organizational Psychology, 24(6), 839-843.

Basu, A., Mitchell, J. S. B., \& Sabhnani, G. K. (2009). Geometric algorithms for optimal airspace design and air traffic controller workload balancing. Journal of Experimental Algorithmics, 14(1), 2-3. https://doi.org/10.1145/1498698.1537598

Benjamin, D. J., Heffetz, O., Kimball, M. S., \& Szembrot, N. (2014). Beyond happiness and satisfaction: Toward well-being indices based on stated preference. American Economic Review, 104(9), 2698-2735. https://doi.org/10.1257/aer.104.9.2698 
INTERNATIONAL JOURNAL OF ACADEMIC RESEARCH IN BUSINESS AND SOCIAL SCIENCES

Vol. 10, No. 5, May, 2020, E-ISSN: 2222-6990 @ 2020 HRMARS

Bongo, M. F., Alimpangog, K. M. S., Loar, J. F., Montefalcon, J. A., \& Ocampo, L. A. (2018). An application of DEMATEL-ANP and PROMETHEE II approach for air traffic controllers' workload stress problem: A case of Mactan Civil Aviation Authority of the Philippines. Journal of Air Transport Management, 68, 198-213. https://doi.org/10.1016/j.jairtraman.2017.10.001

Brink, E. (2009). The relationship between occupational stress, emotional intelligence and coping strategies in air traffic controllers (Doctoral dissertation, Stellenbosch: University of Stellenbosch). http://hdl.handle.net/10019.1/2661

Butler, J., \& Kern, M. L. (2016). The PERMA-Profiler: A brief multidimensional measure of flourishing. International Journal of Wellbeing, 6(3). https://doi.org/10.5502/ijw.v6i3.526

Civil Aviation Authority of Malaysia (CAAM) 2018. Retrieved from

Coffey, J. K., Wray-Lake, L., Mashek, D., \& Branand, B. (2016). A multi-study examination of well-being theory in college and community samples. Journal of Happiness Studies, 17(1), 187-211. https://doi.org/10.1007/s10902-014-9590-8

Ćosić, K., Šarlija, M., Ivkovic, V., Zhang, Q., Strangman, G., \& Popović, S. (2019). Stress Resilience Assessment Based on Physiological Features in Selection of Air Traffic Controllers. IEEE access, 7, 41989-42005. https://doi.org/10.1109/ACCESS.2019.2907479

D'raven, L. L., \& Pasha-Zaidi, N. (2016). Using the PERMA model in the United Arab Emirates. Social indicators research, 125(3), 905-933. https://doi.org/10.1007/s11205-015-0866-0

Dall'Ora, C., Ball, J., Recio-Saucedo, A., \& Griffiths, P. (2016). Characteristics of shift work and their impact on employee performance and wellbeing: A literature review. International journal of nursing studies, 57, 12-27. https://doi.org/10.1016/j.ijnurstu.2016.01.007

Diener, E., Oishi, S., \& Tay, L. (2018). Advances in subjective well-being research. Nature Human Behaviour, 2(4), 253.https://doi.org/10.1038/s41562-018-0307-6

Dodge, R., Daly, A. P., Huyton, J., \& Sanders, L. D. (2012). The challenge of defining wellbeing. International journal of wellbeing, 2(3). https://doi.org/10.5502/ijw.v2i3.4

Duygulu, E., Ciraklar, N. H., Guripek, E., \& Bagiran, D. (2013). The effect of role stress on the employee's well-being: a study in the pharmaceutical companies in the city of Izmir. ProcediaSocial and Behavioral Sciences, 84, 1361-136. https://doi.org/10.1016/j.sbspro.2013.06.757

Federal Aviation Administrations, 2018. Retrieved from https://www.faa.gov/

Folkard, S., Robertson, K.A., Spencer, M.B., 2007. A Fatigue/Risk Index to assess work schedules. Somnologie 11(3), 177-185. https://doi.org/10.1007/s11818-007-0308-6

Forgeard, M. J., Jayawickreme, E., Kern, M. L., \& Seligman, M. E. (2011). Doing the right thing: Measuring wellbeing for public policy. International journal of wellbeing,1(1). https://doi.org/10.5502/ijw.v1i1.15

Harter, J. K., Schmidt, F. L., \& Keyes, C. L. (2003). Well-being in the workplace and its relationship to business outcomes: A review of the Gallup studies. Flourishing: Positive psychology and the life well-lived, 2, 205-224. https://doi.org/10.1037/10594-009

Hetland, H., Hetland, J., Schou Andreassen, C., Pallesen, S., \& Notelaers, G. (2011). Leadership and fulfillment of the three basic psychological needs at work. Career Development International, 16(5), 507-523. https://doi.org/10.1108/13620431111168903

http://dx.doi.org/10.1016/j.sbspro.2014.11.088

http://www.dca.gov.my/publications/

https://doi.org/10.1016/j.jairtraman.2012.08.003

https://doi.org/10.1016/j.ssci.2014.11.005 
INTERNATIONAL JOURNAL OF ACADEMIC RESEARCH IN BUSINESS AND SOCIAL SCIENCES

Vol. 10, No. 5, May, 2020, E-ISSN: 2222-6990 @ 2020 HRMARS

https://doi.org/10.1080/1359432X.2015.1071423

https://doi.org/10.1177\%2F0034355217702136

https://doi.org/10.4236/jtts.2011.13007

Jou, R. C., Kuo, C. W., \& Tang, M. L. (2013). A study of job stress and turnover tendency among air traffic controllers: The mediating effects of job satisfaction. Transportation research part E: logistics and transportation review, 57, 95-104.https://doi.org/10.1016/j.tre.2013.01.009

Juniper, B., Bellamy, P., \& White, N. (2011). Testing the performance of a new approach to measuring employee well-being. Leadership \& Organization Development Journal, 32(4), 344-357. https://doi.org/10.1108/01437731111134634

Kern, M. L., Waters, L. E., Adler, A., \& White, M. A. (2015). A multidimensional approach to measuring well-being in students: Application of the PERMA framework. The journal of positive psychology, 10(3), 262 -271.https://doi.org/10.1080/17439760.2014.936962

Khwaja, M. (2020). PERMA and dentistry: a model on how to flourish in practice. BDJ In Practice, 33(3), 26-27. https://www.nature.com/articles/s41404-020-0335-6

Kontogiannis, T., \& Malakis, S. (2013). Strategies in coping with complexity: Development of a behavioural marker system for air traffic controllers. Safety science,57, 2734.https://doi.org/10.1016/j.ssci.2013.01.014

Kuo, C. W., Jou, R. C., \& Lin, S. W. (2012). Turnover intention of air traffic controllers in Taiwan: A note. Journal of Air Transport Management, 25, 50-52.

Kuovo, A. P. R. (2015). Foundations of SWB in turbulent times: A comparison of four European Countries. International Journal of Sociology and Social Policy, 35(1/2), 2-17. https://doi.org/10.1108/IJSSP-01-2014-0005

Mahzan, N., \& Abidin, A. Z. Z. (2015). Examining Navigators' Job Satisfaction in Royal Malaysian Air Force through the Lenses of Herzberg's Motivation-Hygiene Theory. Journal of Economics, Business and Management, 3(8), 758-762. http://eprints.um.edu.my/id/eprint/13404

Moon, W. C., Yoo, K. E., \& Choi, Y. C. (2011). Air traffic volume and air traffic control human errors. Journal of Transportation Technologies, 1(03), 47.

Öge, E., Cetin, M., \& Top, S. (2018). The effects of paternalistic leadership on workplace loneliness, work family conflict and work engagement among air traffic controllers in Turkey. Journal of air transport management, 66, 25-35. https://doi.org/10.1016/j.jairtraman.2017.10.003

Othman, A. K., Noordin, F., Lokman, A. M., Jaafar, N., \& Mohd, I. H. (2018, March). Conceptualization of happiness index model. In International Conference on Kansei Engineering \& Emotion Research, 833-838. https://doi.org/10.1007/978-981-10-8612-0_86.

Page, K. M., \& Vella-Brodrick, D. A. (2009). The "what", "why" and "how" of employee well-being: A new model. Social Indicators Research, 90(3), 441-458. https://doi.org/10.1007/s11205-0089270-3

Sanda, M. A. (2018). Relevance of air-traffic controllers' tacit knowledge in enhancing air-traffic control and safety in Ghanaian airspace. International Journal of Human Factors Modelling and Simulation, 6(2-3), 103-118. https://doi.org/10.1504/IJHFMS.2018.093170

Seligman, M. E. (2012). Flourish: A visionary new understanding of happiness and well-being. Simon and Schuster. ISBN 1439190771, 9781439190777

Slavin, S. J., Schindler, D., Chibnall, J. T., Fendell, G., \& Shoss, M. (2012). PERMA: A model for institutional leadership and culture change. Academic Medicine,87(11), 1481. https://doi.org/10.1097/ACM.0b013e31826c525a 
INTERNATIONAL JOURNAL OF ACADEMIC RESEARCH IN BUSINESS AND SOCIAL SCIENCES

Vol. 10, No. 5, May, 2020, E-ISSN: 2222-6990 @ 2020 HRMARS

Slemp, G. R., \& Vella-Brodrick, D. A. (2013). Optimising Employee Mental Health: The Relationship Between Intrinsic Need Satisfaction, Job Crafting, and Employee Well-Being. Journal of Happiness Studies, 1-21. https://doi.org/10.1007/s10902-013-9458-3

Tansey, T. N., Smedema, S., Umucu, E., Iwanaga, K., Wu, J. R., Cardoso, E. D. S., \& Strauser, D. (2018). Assessing college life adjustment of students with disabilities: application of the PERMA framework. Rehabilitation Counseling Bulletin, 61(3), 131-142.

Tehrani, N., Humpage, S., Willmott, B., \& Haslam, I. (2007). What's happening with well-being at work. Change Agenda. London: Chartered Institute of Personal Development. http://www.mentalhealthpromotion.net/resources/what-happening-with-well-being-atwork.pdf

Teperi, A.-M., Leppänen, A., \& Norros, L. (2015). Application of new human factors tool in an air traffic management organization. Safety Science, 73, 23-33.

Tobaruela, G., Schuster, W., Majumdar, A., Ochieng, W. Y., Martinez, L., \& Hendrickx, P. (2014). A method to estimate air traffic controller mental workload based on traffic clearances. Journal of Air Transport Management, 39, 59-71. https://doi.org/10.1016/j.jairtraman.2014.04.002

Tomic, I., \& Liu, J. (2017). Strategies to overcome fatigue in air traffic control based on stress management. Int. J. Eng. Sci., 6(4), 48-57. https://doi.org/10.9790/1813-0604014857

Unit, E. P. (2015). Eleventh Malaysia plan, 2016-2020: Anchoring growth on people. Putrajaya, Pencetakan Nasional Malaysia Berhad.

US Department of Labor, \& Bureau of Labor Statistics. (2010). Occupational Outlook Handbook 20102011. JIST Publishing.

Watanabe, K., Kawakami, N., Shiotani, T., Adachi, H., Matsumoto, K., Imamura, K., ... \& Kagami, T. (2018). The Japanese Workplace PERMA-Profiler: a validation study among Japanese workers. Journal of occupational health. https://doi.org/10.1539/joh.2018-0050-OA

Yang, Q., \& Dattel, A. R. (2017). Task Complexity and Time Pressure Affect Air Traffic Controller's Performance and Workload. In 19th International Symposium on Aviation Psychology, 359364. https://corescholar.libraries.wright.edu/isap_2017/1

Yogeesvaran, K. (2013). The Malayisan Well-being Report 2013. Economic Planning Unit: Prime Minister's Department.

Zakaria, M., Abdulatiff, N. K., \& Ali, N. (2014). The role of wellbeing on performance in services sector. Procedia-Social and Behavioral Sciences, 164, 358-365.

Zheng, X., Zhu, W., Zhao, H., \& Zhang, C. (2015). Employee well-being in organizations: Theoretical model, scale development, and cross-cultural validation.Journal of Organizational Behavior, 36(5), 621-644. https://doi.org/10.1002/job.1990. 